\title{
Effect of Different Commercial Oligosaccharides on the Fermentation Properties in Kefir during Fermentation
}

\author{
Nam Su Oh, Hyun Ah Lee, Jae Hee Myung, Ji Young Lee, Jae Yeon Joung, \\ Yong Kook Shin, and Seung Chun Baick* \\ $R \& D$ center, Seoul Dairy Cooperative, Ansan 425-839, Korea
}

\begin{abstract}
Kefir is traditional fermented milk produced by various lactic acid bacteria (LAB) and yeast, which produce lactic acid, ethanol, carbon dioxide, and other flavor compounds. The purpose of this study was to evaluate the effects of different commercial oligosaccharides, such as maltotriose, fructooligosaccharide (FOS), galactooligosaccharide (GOS), and isomaltooligosaccharide (IMO), on the fermentation properties of kefir. First, we determined the acidification kinetic parameters, such as $\mathrm{V}_{\max }, \mathrm{t}_{\max }(\mathrm{h}), \mathrm{t}_{\mathrm{pH} 5.0}(\mathrm{~h})$, and $\mathrm{t}_{\mathrm{f}}(\mathrm{h})$ of fermented milk supplemented with $4 \%(\mathrm{w} / \mathrm{w})$ of different oligosaccharides. The probiotic survival and chemical composition ( $\mathrm{pH}$, organic acids profile, and ethanol content) of kefir during fermentation were also measured. Compared to control fermentation, all oligosaccharides increased acidification rate and reduced the time to complete fermentation ( $\mathrm{pH}$ 4.7). The addition of FOS, in particular, resulted in the lowest $\mathrm{t}_{\mathrm{f}}(\mathrm{h})$ and the highest populations of LAB and yeast during fermentation. All oligosaccharides increased ethanol production during fermentation. Further, significant differences were observed in the formation rates of six organic acids during fermentation. This study provided comparative data on the properties of commercial oligosaccharides for kefir manufacturing. Consequently, FOS especially had the potential for adequate and effective oligosaccharides in commercial kefir for the improvement of cost- and time-effectiveness.
\end{abstract}

Key words: oligosaccharide, kefir, fermentation, fructooligosaccharide

\section{Introduction}

Kefir is a traditional fermented milk product originating from the Caucasus mountains. There are two primary ways of making kefir: fermenting by kefir grains or by commercial starter cultures (Thoreux \& Schmucker, 2001). Originally, kefir was made by inoculating milk with kefir grain, which is irregularly shaped yellowish-white hard granules (Güzel-Seydim et al., 2000). A kefir grain consists of bacteria and yeast species such as Lactobacillus helveticus, Lactobacillus delbrueckii subsp. bulgaricus, Lactococcus lactis subsp. lactis, Leuconostoc mesenteroides subsp. cremoris, and Kluyveromyces marxianus. The biomass of kefir grains slowly increases during fermentation (Gorek \& Tramek, 2007). These days, due to economic effectiveness, including the time-saving and hygienic manufacturing process, commercial direct-to-vat cultures are utilized. Microbial populations of kefir produce lactic

*Corresponding author: Seung Chun Baick, R\&D center, Seoul Dairy Cooperative, Ansan 425-839, Korea. Tel: 82-31-4913867, Fax: 82-31-491-9179, E-mail: baicksc@seoulmilk.co.kr acid, ethanol, carbon dioxide, and other flavor compounds, such as acetaldehyde, acetoin and diacetyl, which produce the unique kefir flavor. It has been reported that kefir can be considered a probiotic resource as it can improve a variety of health conditions (Rodrigues et al., 2005). The reported scientific benefits of kefir include: antioxidant activity (Liu et al., 2005a; Liu et al., 2005b), antipathogenic activity (Millette et al., 2007), antitumor (Kubo et al., 1992), anticarcinogenic activity (Sarkar, 2007), and anti-inflammatory/ immunomodulatory effects (Lee et al., 2007; Thoreux \& Schmucker, 2001). Prebiotics are non-digestible food ingredients that beneficially affect the host by selectively stimulating the growth and/ or activity of probiotics, thus improving host health (Gibson \& Roberfroid, 1995). A prebiotic substrate must not be hydrolyzed or absorbed in the stomach or small intestine; fermentation of the substrate should induce beneficial effects within the host. In terms of diet, resistant starch, non-starch polysaccharides, sugars, and oligosaccharides are representative prebiotics. Oligosaccharides are sugars consisting of approximately 2 to 20 saccharide units, and the following oligomers have been suggested to 
have prebiotic potential: lactulose, fructooligosaccharide (FOS), galactooligosaccharide (GOS), soybean oligosaccharide, isomaltooligosaccharide (IMO), glucooligosaccharide and xylooligosaccharide (Manning and Gibson, 2004).

The aim of this study was to evaluate the effects of various commercial oligosaccharides on the fermentation properties of kefir, including acidification kinetics, the population of lactic acid bacteria and yeast, as well as ethanol and organic acid production during kefir fermentation.

\section{Materials and Methods}

\section{Kefir sample preparation}

Kefir starter cultures were purchased from Christian Hansen (Hørsholm, Denmark); XPL-1 and LAF-4. XPL1 included Lactococcus lactis subsp. cremoris, Lactococcus lactis subsp. lactis, Lactococcus lactis subsp. lactis biovariety diacetylactis, Leuconostoc mesenteroides, and Streptococcus thermophilus and LAF-4 included Kluyveromyces marxianus subsp. marxianus. The inoculation concentration of XPL-1 and LAF-4 were $250 \mathrm{U} / \mathrm{L}$ and $4 \mathrm{U} / \mathrm{L}$, respectively. After inoculation to pasteurized milk, milk was incubated at $31^{\circ} \mathrm{C}$. The desired final $\mathrm{pH}$ of the product was $\mathrm{pH}$ 4.7. Samples were collected every hour for analysis of kinetic parameters and four times for analysis of bacterial and yeast counts, organic acid and ethanol contents during fermentation.

\section{Oligosaccharides}

The following commercial oligosaccharides were supplemented at the concentration of $4 \%(\mathrm{w} / \mathrm{w})$; IMO (purity $>69 \%$, Daesang Co-Op., Korea), FOS (purity $>55 \%$, Samyanggenex, Korea), maltotriose (purity $>60 \%$, Daesang Co-Op., Korea), GOS (purity $>53 \%$, Ingredion, Korea).

\section{Kinetic parameters}

The acidification rate $\left(\mathrm{V}_{\text {max }}\right)$ was calculated as the time variation of $\mathrm{pH}(d \mathrm{pH} / d \mathrm{t})$ and expressed as $10^{-3} \mathrm{pH}$ units/ h. During the fermentation period, the following kinetic parameters were also calculated: (i) $t_{\max }(h)$, time at which $\mathrm{V}_{\text {max }}$ was reached; (ii) $\mathrm{t}_{\mathrm{pH} 5.0}(\mathrm{~h})$, time to reach $\mathrm{pH}$ 5.0; and (iii) $t_{f}(h)$, time to complete the fermentation.

\section{Bacterial and yeast counts}

Lactic acid bacteria and yeast counts were carried out in triplicate after 1, 6, 12, $14 \mathrm{~h}$-fermentation. Samples were diluted with sterile saline solution and plated on sterile BCP agar (Eiken chemical Co., Japan) for $3 \mathrm{~d}$ at $37^{\circ} \mathrm{C}$ and on sterile Potato dextrose agar (Difco ${ }^{\mathrm{TM}}$, USA) for $5 \mathrm{~d}$ at $24^{\circ} \mathrm{C}$ to determine lactic acid bacteria and yeast counts, respectively.

\section{Ethanol and organic acid content}

Samples were analyzed for ethanol production using GC-FID (Agilent, USA) according to the method of GüzelSeydim et al. (2000). In addition, concentrations of lactic, acetic, citric, succinic, pyruvic, and formic acids in kefir during fermentation were determined using high-performance liquid chromatography (HPLC). Sample extraction was performed according to the method of KocaogluVurma et al. (2008). A HPLC system (Nanospace I, Shiseido, Japan) equipped with UV-VIS detector monitored at $210 \mathrm{~nm}$, and organic acids were analyzed onto an C18column (Capcellpak C18 UG120, 4.6×150 mm, $5 \mu \mathrm{m}$, Shiseido) and kept at $35^{\circ} \mathrm{C}$. The mobile phase was $0.1 \%$ $\mathrm{H}_{3} \mathrm{PO}_{4}$ in 97.5:2.5 (v/v) water: acetonitrile. Run time was $20 \mathrm{~min}$ at $1 \mathrm{~mL} / \mathrm{min}$ and the injection volume was $7 \mu \mathrm{L}$. Peak identities were determined based on retention time of standard compounds and concentrations of individual organic acids were quantified by using a standard curve for each compound relating peak area to the concentration.

\section{Statistical analysis}

All analysis was conducted in triplicate, and significant differences expressed as different letters were analyzed using Duncan's multiple range test. SAS statistical package was used to perform all statistical tests (SAS Inst., 2010). Values of $p<0.05$ were considered to indicate a significant difference.

\section{Results and Discussion}

\section{Kinetic parameters}

The results of acidification kinetic parameters by different oligosaccharides, including FOS, GOS, maltotriose and IMO, are compared in Table 1. Values of $\mathrm{V}_{\max }$ ranged from $309.33 \pm 5.13$ to $469.00 \pm 8.72 \times 10^{-3} \mathrm{pH}$ units $/ \mathrm{h}$. Among the samples, the $\mathrm{V}_{\max }$ of the sample added to FOS was significantly higher than others as $469.00 \pm 8.72 \times 10^{-3} \mathrm{pH}$ units/h. Other than FOS, $\mathrm{V}_{\max }$ values for other oligosaccharides-supplemented samples were lower than the control. The time to reach $\mathrm{V}_{\max }\left(\mathrm{t}_{\max }\right)$ of oligosaccharidessupplemented samples was shorter than the control, except in the case of maltotriose. In particular, the FOS and IMO-supplemented samples reached $\mathrm{V}_{\max }$ more rapidly than the other supplemented groups as $8.33 \pm 0.58 \mathrm{~h}$. 
Table 1. Acidification kinetic parameters of kefir supplemented with $4 \%$ (w/w) FOS, GOS, maltotriose, and IMO

\begin{tabular}{ccccc}
\hline \hline Prebiotics & $\mathrm{V}_{\max }\left(10^{-3} \mathrm{pH}\right.$ units/h) & $\mathrm{t}_{\max }(\mathrm{h})$ & $\mathrm{t}_{\mathrm{pH} 5.0}(\mathrm{~h})$ & $\mathrm{t}_{\mathrm{f}}(\mathrm{h})$ \\
\hline Control & $421.67^{\mathrm{d}} \pm 7.64$ & $10.67^{\mathrm{b}} \pm 0.58$ & $12.51^{\mathrm{c}} \pm 0.15$ & $15.59^{\mathrm{e}} \pm 0.13$ \\
FOS & $469.00^{\mathrm{e}} \pm 8.72$ & $8.33^{\mathrm{a}} \pm 0.58$ & $9.61^{\mathrm{a}} \pm 0.05$ & $11.65^{\mathrm{a}} \pm 0.06$ \\
GOS & $328.33^{\mathrm{b}} \pm 12.58$ & $9.00^{\mathrm{a}} \pm 0.00$ & $11.45^{\mathrm{b}} \pm 0.05$ & $14.01^{\mathrm{c}} \pm 0.11$ \\
Maltotriose & $359.00^{\mathrm{c}} \pm 3.61$ & $11.33^{\mathrm{b}} \pm 0.58$ & $11.60^{\mathrm{b}} \pm 0.11$ & $13.35^{\mathrm{b}} \pm 0.18$ \\
IMO & $309.33^{\mathrm{a}} \pm 5.13$ & $8.33^{\mathrm{a}} \pm 0.58$ & $11.63^{\mathrm{b}} \pm 0.11$ & $14.65^{\mathrm{d}} \pm 0.06$ \\
\hline
\end{tabular}

Values are expressed as the mean \pm standard deviations (S.D) $(n=3)$.

Different letters in the same column indicate a statistically significant difference among values of the same parameter $(p<0.05)$.

It seems that these two oligosaccharides, FOS and IMO, made it possible to boost the rate of acidification during kefir fermentation. In addition, the time to complete the fermentation of experimental samples with oligosaccharides was shorter than the control, ranging from 11.65 \pm 0.06 to $14.65 \pm 0.13 \mathrm{~h}$. The fermentation of kefir was also more rapidly completed in the FOS-supplemented sample as $11.65 \pm 0.06 \mathrm{~h}$. A reduction in the $\mathrm{t}_{\mathrm{f}}$ and $\mathrm{t}_{\mathrm{pH} 5.0}$ values of the FOS-supplemented sample occurred by approximately $25 \%$ and $23 \%$, respectively, compared to control at the end of fermentation. According to the results from comparing kinetics, oligosaccharides, especially FOS, could be appropriate prebiotic ingredients for kefir preparation in terms of acidification and fermentation time, according to this study. Similarly, various other prebiotics, such as inulin, maltodextrin, oligofructose and polydextrose, have been reported to accelerate acidification rate (De Souza Oliveira et al., 2009; Oliveira et al., 2009).

\section{Bacterial and yeast counts}

Lactic acid bacterial and yeast counts showed that the

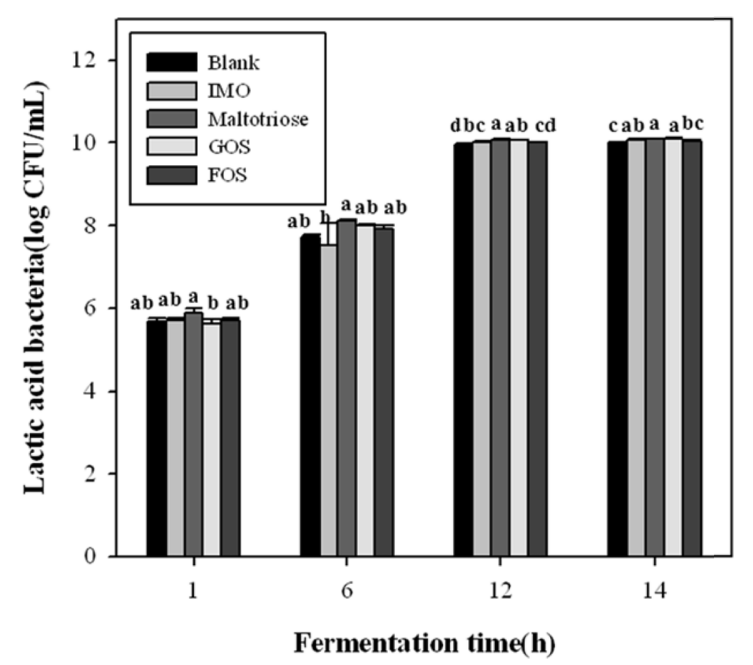

Fig. 1. Cell counts of lactic acid bacteria in kefir supplemented with $4 \%(w / w)$ FOS, GOS, maltotriose and IMO during fermentation. Different letters indicate a statistically significant difference $(\boldsymbol{p}<\mathbf{0 . 0 5})$. counts from the control and supplemented groups were increased by fermentation time with the same patterns (Figs. 1 and 2). There was no significant difference in the population of lactic acid bacteria between oligosaccharides-supplement groups and the control. After 1 hourfermentation, lactic acid bacteria counts ranged from $5.63 \pm 0.13$ to $5.87 \pm 0.11 \mathrm{Log} \mathrm{CFU} / \mathrm{mL}$. The lactic acid bacterial counts gradually increased by fermentation time, until $12 \mathrm{~h}$, stopped proliferation, and reached the stationary phase after approximately $12 \mathrm{~h}$, ranging from 9.96 0.02 to $10.09 \pm 0.04 \mathrm{Log} C F U / \mathrm{mL}$. In the results from the yeast counts, it seems these also gradually increased during fermentation, and another significant difference was observed in yeast counts at the end of fermentation. The highest counts of yeast were found in the FOS-supplemented group by $4.04 \pm 0.02 \mathrm{Log} \mathrm{CFU} / \mathrm{mL}$, while the lowest were found in the control by $3.72 \pm 0.03 \mathrm{Log} \mathrm{CFU} / \mathrm{mL}$. These data suggested that FOS contributed to the viability of yeast but not to the viability of lactic acid bacteria. Moreover, results from previous studies reported the effects of prebiotics on the growth of lactic acid bacteria

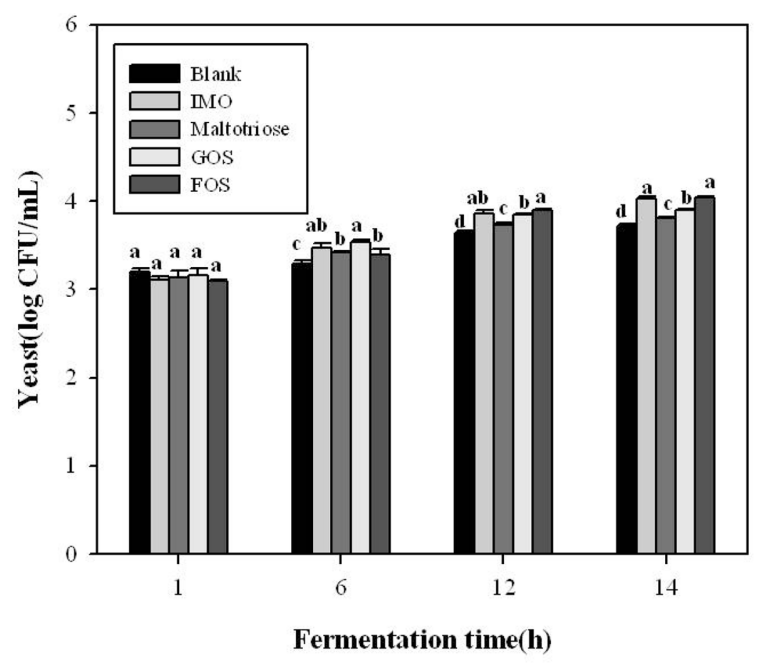

Fig. 2. Cell counts of yeast of kefir supplemented with $4 \%$ (w/ w) FOS, GOS, maltotriose, and IMO during fermentation. Different letters indicate a statistically significant difference $(p<0.05)$. 
during refrigerated storage (Martínez-Villaluenga et al., 2006). According to the aforementioned study, the addition of raffinose family oligosaccharides (RFOs) increased Bifidobacterium lactis $\mathrm{Bb}-12$ at final fermentation time, compared to the control, while Lactobacillus acidophilus showed no differences in the presence of RFOs. Further, they indicated that RFOs, as prebiotics, also increased acidification rate so that coagulation time was shortened and textural characteristics of yogurt were improved because the syneresis of whey was limited. These results closely coincided with the results of our studies.

\section{Ethanol and organic acid content}

The yeasts isolated from kefir can be classified as either lactose-fermenting or non-lactose-fermenting, and nonlactose fermenting yeasts dominate. Kluyveromyces marxianus subsp. marxianus used in this study is included in the primary lactose-fermenting yeast groups. The yeasts are primarily responsible for the production of ethanol and $\mathrm{CO}_{2}$ in kefir (Roginski et al., 2003). Moreover, the hetero-fermentative lactic acid bacteria produce ethanol as well as lactic acid from the fermentation of lactose, including Lactobacillus lactis and Leuconostoc mesenteroides subsp. cremoris (Roginski et al., 2003). In this study, the ethanol content of kefir was measured during fermentation in order to compare the effects of different oligosaccharides. The ethanol content of kefir supplemented with different oligosaccharides was found to increase gradually during fermentation. Interestingly, ethanol content from the FOS-supplemented sample was significantly higher than other oligosaccharides (Fig. 3). After 1-hour fermentation, ethanol content of the FOS-

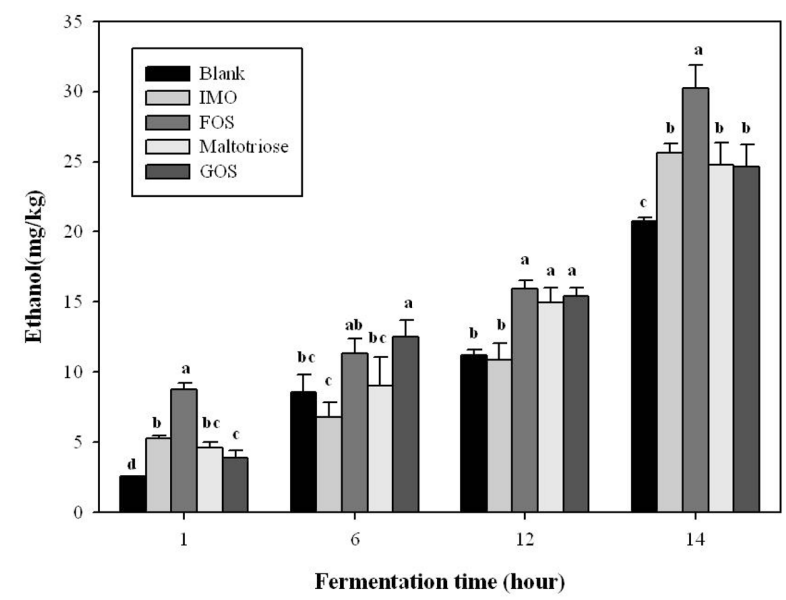

Fig. 3. Ethanol production in kefir supplemented with $4 \%$ (w/ w) FOS, GOS, maltotriose, and IMO during fermentation. Different letters indicate a statistically significant difference $(p<0.05)$. supplemented sample showed the highest amount by $8.72 \pm 0.51 \mathrm{mg} / \mathrm{kg}$ among the supplemented groups; it also showed the highest amount by $30.22 \pm 1.68 \mathrm{mg} / \mathrm{kg}$ at the end of fermentation. These results were related to the results of acidification kinetics. Liu and Lin (2000) investigated the effects of the addition of different carbohydrates on the growth characteristics of kefir grains in soymilk. They found that the addition of $1 \%$ glucose or lactose to soymilk increased the yeast population from 4.7 $\pm 0.2 \mathrm{Log} C F U / \mathrm{mL}$ to $6.4 \pm 0.1 \mathrm{Log} C F U / \mathrm{mL}$ at the end of fermentation. The production of ethanol, meanwhile, enhanced by added glucose or lactose from $0.11 \pm 0.01 \%$ to $0.25 \%$. These results suggested that the ethanol production rate was not necessarily in direct proportion to the increase rate of yeast.

The major end products of fermentation are organic acids, such as lactic acid, pyruvic acid, acetoin, diacetyl, ethanol, and $\mathrm{CO}_{2}$ (Vedamuthu, 1977). Organic acids, in particular, are important to the final properties of processed foods, especially fermented dairy products. These are also responsible for sensory characteristics as well as natural preservatives; lactic acid has been proven to inhibit certain pathogenic bacteria in yogurt (Rubin et al., 1982). Lactic acid produces a slightly acidic taste, and its mixture with ethanol and other flavor products creates the unique flavor of kefir (Fernandez-Garcia \& McGregor, 1994; Güzel-Seydim et al., 2000). Lactose is readily degraded to galactose and glucose by Group $\mathrm{N}$ streptococci.

The results of organic acid content showed that the concentration of formic acid and citric acid gradually decreased, while the concentration of lactic acid, acetic acid, and pyruvic acid increased with same patterns between different oligosaccharides. However, succinic acid concentration did not show significant differences during fermentation (Fig. 4). Güzel-Seydim et al. (2000) also reported that pyruvic acid and lactic acid content increased slightly, whereas citrate content decreased during fermentation. Strains of Lactococcus lactis subsp. lactis biovariety diacetylactis, as well as some species belonging to Leuconostoc and Weissella genera, are well known for lactic acid bacteria which possess a citrate utilization pathway (Mayo et al., 2008). Further, Lactobacillus lactis subsp. lactis and Lactobacillus lactis subsp. cremoris, used in this study, are representative homo-fermentative lactic acid bacteria which use the Embden-MeyerhoffParnas (EMP) pathway to produce pyruvic and lactic acids (Roginski et al., 2003). In the homo-fermentative pathway, glucose is further metabolized by the EMP pathway to pyruvate (Güzel-Seydim et al., 2000). However, 

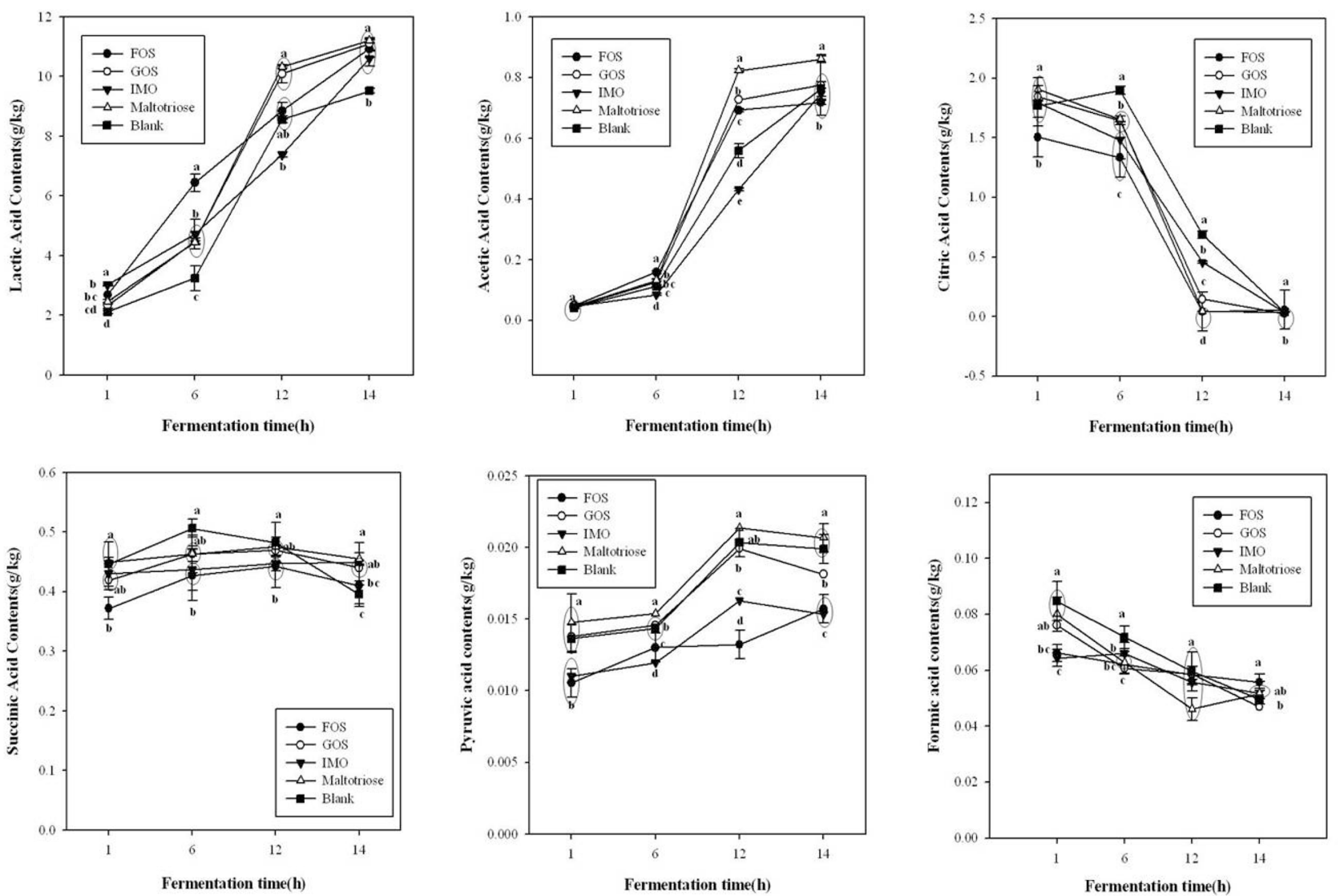

Fig. 4. Concentration of organic acids in kefir supplemented with $4 \%$ (w/w) FOS, GOS, maltotriose, and IMO during fermentation. Different letters indicate a statistically significant difference $(p<0.05)$.

significant differences were not found in the levels of six organic acids at the end of fermentation among different oligosaccharide-supplemented samples. Meanwhile, significant differences were observed in their formation rates during fermentation. Regardless of oligosaccharide types, the addition of oligosaccharides had no significant effect on the concentration of organic acid during fermentation. Relevant studies of the effect of RFOs on organic acid content from fermented milk previously exhibited (Martínez-Villaluenga et al., 2006). It showed that significantly higher levels of lactic and acetic acids were found in the fermented milk containing RFOs at 1 and $7 \mathrm{~d}$ of refrigerated storage, compared to the control. For further exploration, a study of the effect of oligosaccharide in kefir during refrigerated storage will need to be conducted.

\section{Conclusion}

This study provided comparative data on the properties of commercial oligosaccharides for kefir manufacturing. The addition of oligosaccharides, particularly FOS, could contribute to accelerating the acidification and fermenta- tion of kefir; FOS had better beneficial effects on the growth of probiotics in kefir and produced higher amounts of ethanol compared to other oligosaccharides. However, the concentrations of organic acid such as lactic acid, acetic acid, pyruvic acid, formic acid, citric acid, and succinic acid were not influenced by oligosaccharides at the end of fermentation. Thus, FOS has the potential to act as an adequate and effective prebiotic in commercial kefir with time- and cost-effectiveness. However, to provide more convincing evidence, further studies will be necessary with regard to the effects of oligosaccharides on post-acidification of kefir during refrigerated storage.

\section{References}

1. De Souza Oliveira, R. P., Perego, P., Converti, A., and De Oliveira, M. N. (2009) Growth and acidification performance of probiotics in pure culture and co-culture with Streptococcus thermophilus: The effect of inulin. LWT-Food Sci. Technol. 42, 1015-1021.

2. Fernandez-Garcia, E. and McGregor, J. U. (1994) Determination of organic acids during the fermentation and cold storage of yogurt. J. Dairy Sci. 77, 2934-2939. 
3. Gibson, G. R. and Roberfroid, M. B. (1995) Dietary modulation of the human colonic microbiota: introducing the concept of prebiotics. J. Nutr. 125, 1401-1412.

4. Gorek, A. and Tramek, M. (2007) Quantitative examination of process parameters during kefir grain biomass production. Int. J. Chem. React Eng. 5.

5. Güzel-Seydim, Z., Seydim, A. C., and Greene, A. K. (2000) Organic acids and volatile flavor components evolved during refrigerated storage of kefir. J. Dairy Sci. 83, 275-277.

6. Güzel-Seydim, Z. B., Seydim, A. C., Greene, A. K., and Bodine, A. B. (2000) Determination of organic acids and volatile flavor substances in Kefir during fermentation. J. Food Compos. Anal. 13, 35-43.

7. Kocaoglu-Vurma, N. A., Harper, W. J., Drake, M. A., and Courtney, P. D. (2008) Microbiological, chemical, and sensory characteristics of Swiss cheese manufactured with adjunct Lactobacillus strains using a low cooking temperature. J. Dairy Sci. 91, 2947-2959.

8. Kubo, M., Odani, T., Nakamura, S., Tokumaru, S., and Matsuda, H. (1992) Pharmacological study on kefir-a fermented milk product in Caucasus. I. On antitumor activity (1). Yakugaku zasshi. 112, 489-495.

9. Lee, M. Y., Ahn, K. S., Kwon, O. K., Kim, M. J., Kim, M. K., Lee, I. Y., Oh, S. R., and Lee, H. K. (2007) Anti-inflammatory and anti-allergic effects of kefir in a mouse asthma model. Immunobiology, 212, 647-654.

10. Liu, J. R., Chen, M. J., and Lin, C. W. (2005a) Antimutagenic and antioxidant properties of milk-kefir and soymilk-kefir. $J$. Agric. Food Chem. 53, 2467-2474.

11. Liu, J. R. and Lin, C. W. (2000) Production of kefir from soymilk with or without added glucose, lactose, or sucrose. $J$. Food Sci., 65, 716-719.

12. Liu, J. R., Lin, Y. Y., Chen, M. J., Chen, L. J., and Lin, C. W. (2005b) Antioxidative activities of kefir. Asian-Austral. J. Anim. Sci. 18, 567-573.

13. Manning, T. S. and Gibson, G. R. (2004) Prebiotics. Best Pract.
Res. Clin. Gastroenterol. 18, 287-298.

14. Martínez-Villaluenga, C., Frías, J., Gómez, R., and Vidal-Valverde, C. (2006) Influence of addition of raffinose family oligosaccharides on probiotic survival in fermented milk during refrigerated storage. Int. Dairy J. 16, 768-774.

15. Mayo, B., López, P., and Pérez-Martínez, G. (2008) Molecular aspects of lactic acid bacteria for traditional and new applications. Research Signpost. Kerala, India, pp. 65-88.

16. Millette, M., Luquet, F. M., and Lacroix, M. (2007) In vitro growth control of selected pathogens by Lactobacillus acidophilus- and Lactobacillus casei-fermented milk. Lett. Appl. Microbiol. 44, 314-319.

17. Oliveira, R. P. S., Florence, A. C. R., Silva, R. C., Perego, P., Converti, A., Gioielli, L. A., and Oliveira, M. N. (2009) Effect of different prebiotics on the fermentation kinetics, probiotic survival and fatty acids profiles in nonfat symbiotic fermented milk. Int. J. Food Microbiol. 128, 467-472.

18. Rodrigues, K. L., Carvalho, J. C., and Schneedorf, J. M. (2005) Anti-inflammatory properties of kefir and its polysaccharide extract. Inflammopharmacology 13, 485-492.

19. Roginski, H., Fuquay, J. W., and Fox, P. F. (2003) Encyclopedia of dairy sciences. Volumes 1-4. Academic Press.

20. Rubin, H. E., Nerad, T., and Vaughan, F. (1982) Lactic acid inhibition of Salmonella typhimurium in yogurt. J. Dairy Sci. 65, 197-203.

21. Sarkar, S. (2007) Potential of kefir as a dietetic beverage-A review. Br. Food J. 109, 280-290.

22. SAS. (2010) SAS/STAT Software for PC. Release 9.2, SAS Institute Inc., Cary, NC, USA.

23. Thoreux, K. and Schmucker, D. L. (2001) Kefir milk enhances intestinal immunity in young but not old rats. J. Nutr. 131, 807-812.

24. Vedamuthu, E. (1977) Exotic fermented dairy foods. J. Food Prot. 40.

(Received 2012.12.13/Revised 2013.4.12/Accepted 2013.5.16) 